\title{
A new method to suppress the DC power supply voltage ripple
}

\author{
Ding Ping ${ }^{1,}$ a, Ma Xiaoming ${ }^{2, b}$ \\ ${ }^{1}$ PLA,NO.92941 Troop, Huludao, China \\ 2 PLA,NO.92941 Troop,Huludao,China \\ amading_2006@126.com, b7109910@qq.com
}

Keywords: double pulse width modulation DC power supply voltage ripple

Abstract. With the development of power electronics technology, how to improve the output quality of DC power supply has become an important subject of recent scholars' research. This paper put forward a new PWM control mode, the DC power supply output ripple is effectively suppressed. The theoretical basis is given by the principle analysis. Finally, the accuracy of the theoretical analysis is verified by simulation.

\section{Introduction}

With the development of power electronics technology, how to improve the output quality of DC power supply has become an important subject of recent scholars' research. DC power output ripple is too large mainly have the following effects : the capacitor load caused by resonance and harmonic current amplification, resulting in the capacitor due to overload or over-voltage damage; so that some electrical equipment, especially precision instruments and equipment work is not normal, or even damage; resulting in energy measurement and other detection instrument error.

Taking the Buck circuit as the research object, this paper presents a new type of PWM control mode, which can effectively suppress the output voltage ripple of the DC power supply.

\section{Principle of double pulse width modulation}

For the double pulse width modulation method in Figure 1, the first pulse conduction time is ta, the second pulse conduction time is tb, the two pulse interval is tc, and ta tb and tc meet the following relations.

$$
\left\{\begin{array}{l}
t_{a}=D_{o n 1} \times T_{s} \\
t_{c}=D_{o n 2} \times T_{s} \\
D_{o n}=D_{o n 1}+D_{o n 2} \\
t_{b}=D_{\text {int }} \times T_{s}<\left(1-D_{o n}\right) T_{s}
\end{array}\right.
$$

In the formula (1), Don1 is the duty ratio of the first pulse, Don2 is the duty ratio of second pulses, and the ratio of Dint 1 to the interval of two pulses is proportional to the period of control signal. Here we define 2 functions $H(n, D)$ and $G(n, D)$ as follows:

$$
\begin{aligned}
& H(n, D)=\frac{D_{o n 2}}{D_{o n 1}} \\
& G(n, D)=\frac{D_{i n t 1}}{D_{o n 1}}
\end{aligned}
$$

The $\mathrm{H}$ (n, D) for switching period second pulses of the first pulse and the proportion coefficient ratio, G (n, D) for two pulse interval time and the first pulse duration ratio coefficient; according to formula (1), type (2) and type (3) we can conclude that Don1, Don2, Dint1 for mathematical expressions: 


$$
\left\{\begin{array}{l}
D_{o n 1}=\frac{D_{o n}}{1+H(n, D)} \\
D_{o n 2}=\frac{H(n, D) \times D_{o n}}{1+H(n, D)} \\
D_{i n t 1}=\frac{D_{o n} \times G(n, D)}{1+H(n, D)}
\end{array}\right.
$$

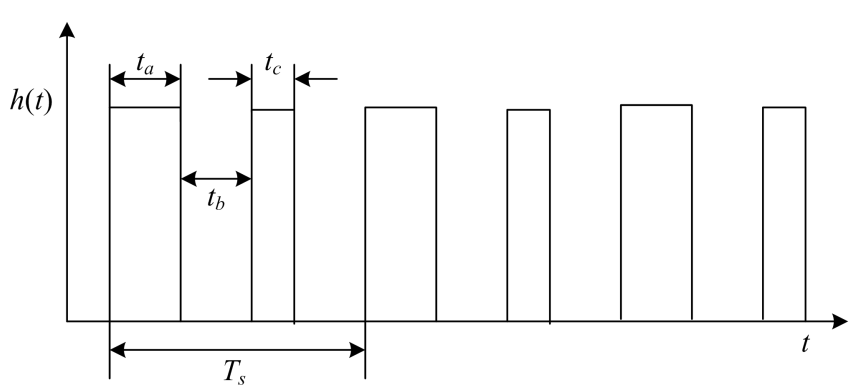

Fig.1 Single pulse modulation

\section{Principle analysis of output voltage ripple}

In order to further study the double pulse width modulation mode, taking Buck circuit as an example, the output current and voltage ripple and output current harmonics of Buck circuit under single pulse width and double pulse width modulation are analyzed and compared. Figure 2 is the schematic diagram of the Buck circuit.

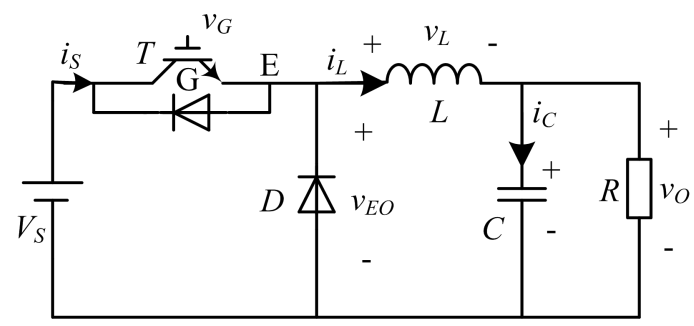

Fig.2 Single pulse modulation

Io is the output current size, the Ts is the switch period, and the Don is the duty cycle of the switch period. The expression of the ripple of the output current in the period is:

$$
\Delta I_{L-\text { single }}=\frac{V_{s} D_{o n}\left(1-D_{o n}\right)}{L f_{s}}
$$

In the form of the switch, the frequency of the switch cycle. The fluctuation of the output voltage in the switch period is as follows:

$$
\Delta V_{o-\text { single }}=\frac{\Delta Q}{C}
$$

For the charge amount of the capacitor in the cycle, $\mathrm{C}$ is the capacitance of capacitance.

We can calculate the charge of the capacitor in the switch period.

$$
\Delta Q=\frac{1}{2} \frac{\Delta I_{L-\text { single }}}{2} \frac{T_{s}}{2}
$$

To bring (7) into (6), we can get:

$$
\Delta V_{o}=\frac{\Delta I_{L-\text { single }} T_{s}}{8 C}
$$

(5), (8) are the expression of the output current and voltage ripple of single pulse width modulation.

There are 4 operating states in a dual pulse width modulation circuit. Figure 3 is the working 
waveforms of the circuit in the double pulse width modulation mode. In the picture, ta is the first time of pulse opening, tb is two pulse time interval, tc is second pulse opening time, td is the time interval between second pulses and the next pulse.

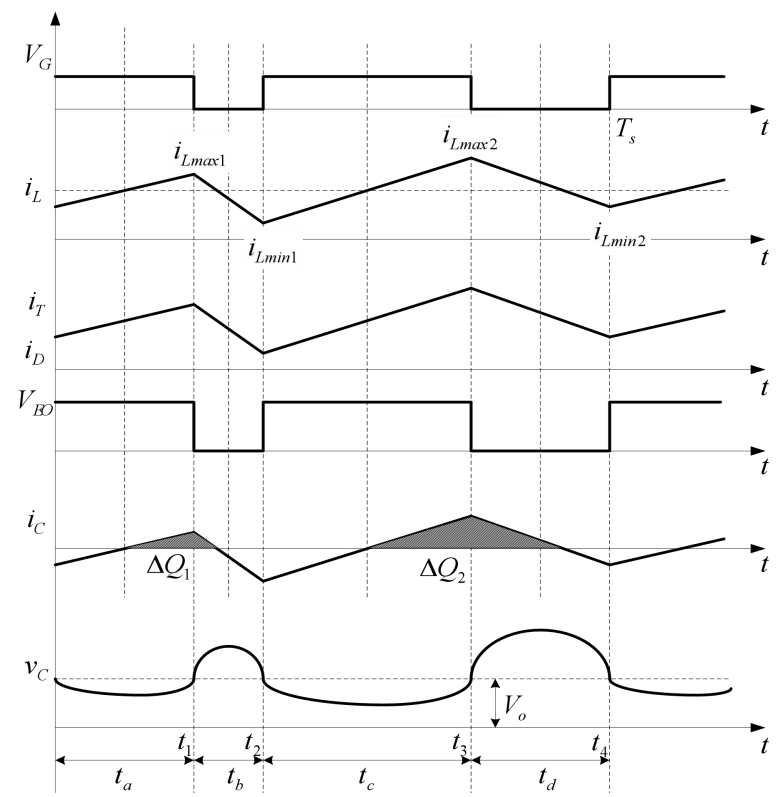

Fig.3 Working principle diagram of double pulse modulation mode

$$
D_{o n 1}+D_{o n 2}=D_{o n}
$$

The relationship between the interval of the pulse and the ratio of the period is as follows:

$$
D_{\text {int } 1}+D_{\text {int } 2}=D_{\text {off }}=1-D_{\text {on }}
$$

In the figure has the type: $t_{d}=D_{i n t 2} \times T_{s}$;

$$
\Delta I_{L-\text { dual }}=\left\{\begin{array}{l}
\frac{V_{s}-V_{o}}{L} t_{a} ;\left(D_{o f f} D_{o n 1}>D_{o n} D_{\text {int } 1} \& \& D_{o f f} D_{o n 2}>D_{o n} D_{\text {int } 2}\right) \\
\frac{V_{o}}{L} t_{b} ;\left(D_{o f f} D_{o n 1}>D_{o n} D_{\text {int } 2} \& \& D_{o f f} D_{o n 2}<D_{o n} D_{\text {int } 2}\right) \\
\frac{V_{s}-V_{o}}{L} t_{c} ;\left(D_{o f f} D_{o n 1}<D_{o n} D_{\text {int } 2} \& \& D_{o f f} D_{o n 2}<D_{o n} D_{\text {int } 2}\right) \\
\frac{V_{s}-V_{o}}{L} t_{a}-\frac{V_{o}}{L} t_{b}+\frac{V_{s}-V_{o}}{L} t_{c} ;\left(D_{o f f} D_{\text {int } 1}<D_{o n} D_{\text {int } 2} \& \& D_{o f f} D_{o n 2}>D_{o n} D_{\text {int } 2}\right)
\end{array}\right.
$$

Put the four type $D_{o n 1}=\frac{D_{o n}}{1+H(n, D)}, \quad D_{o n 2}=\frac{H(n, D) \times D_{o n}}{1+H(n, D)}$,

$D_{\text {int } 1}=\frac{D_{o n} \times G(n, D)}{1+H(n, D)} D_{\text {int } 2}=D_{o f f}-\frac{D_{o n} \times G(n, D)}{1+H(n, D)}$ into (11), then we can obtain:

$$
\Delta I_{L-\text { dual }}=\left\{\begin{array}{l}
\frac{V_{s}-V_{o}}{L} t_{a} ;\left(\frac{G(n, D)}{H(n, D)} D_{o n}>D_{o f f} \& \& D_{o f f}<G(n, D) D_{o n}\right) \\
\frac{V_{o}}{L} t_{b} ;\left(\frac{G(n, D)}{H(n, D)} D_{o n}>D_{o f f}>G(n, D) D_{o n}\right) \\
\frac{V_{s}-V_{o}}{L} t_{c} ;\left(D_{o f f}>\frac{G(n, D)}{H(n, D)} D_{o n} \& \& D_{o f f}>G(n, D) D_{o n}\right) \\
\frac{V_{s}-V_{o}}{L} t_{a}-\frac{V_{o}}{L} t_{b}+\frac{V_{s}-V_{o}}{L} t_{c} ;\left(\frac{G(n, D)}{H(n, D)} D_{o n}<D_{o f f}<G(n, D) D_{o n}\right)
\end{array}\right.
$$


Formula (12) is the relation between output current ripple and function $H(n, D)$ and $G(n, D)$. From the formula, we can see that the output current ripple can be changed by changing function

$H(n, D)$ and $G(n)$.

Put the four type $D_{o n 1}=\frac{D_{o n}}{1+H(n, D)}, \quad D_{o n 2}=\frac{H(n, D) \times D_{o n}}{1+H(n, D)}$,

$D_{\text {int } 1}=\frac{D_{o n} \times G(n, D)}{1+H(n, D)} D_{\text {int } 2}=D_{o f f}-\frac{D_{o n} \times G(n, D)}{1+H(n, D)}$ into (2), then we can obtain:

$$
\Delta I_{L-\text { single }}=\frac{V_{s} D_{o n}\left(1-D_{o n}\right)}{L f_{s}}=\frac{V_{s}-V_{o}}{L}\left(t_{a}+t_{c}\right)=\frac{V_{o}}{L}\left(t_{b}+t_{d}\right)
$$

The comparison between (12) and (13) shows that no matter the value of function $H$ (n, D) and $\mathrm{G}(\mathrm{n}, \mathrm{D})$, the output current ripple of double pulse width modulation circuit is less than that of monopulse modulation mode, namely, output current ripple.

Therefore, we can conclude that double pulse width modulation can effectively suppress the output current ripple of the circuit, and suppress the magnitude of the current ripple, which is determined by the value of function $H(n, D)$ and $G(n, D)$.

From figure 3 , we can see that when iL-dual $>\mathrm{Io}, \mathrm{iC}$ is positive, $\mathrm{C}$ charges, and output voltage

vo-dual rises; when iL-dual < Io, iC is negative, $\mathrm{C}$ discharge and output voltage vo-dual decrease, so the capacitor suppression is in cyclic charge and discharge state. If the filter capacitor $\mathrm{C}$ is large enough, the vo-dual can be regarded as a constant DC voltage Vo-dual. When the $\mathrm{C}$ is not very large, the vo-dual has a certain pulse, and the waveform in the diagram shows that the charge charge of the capacitor $\mathrm{C}$ in a switch period is:

$$
\begin{gathered}
\Delta Q_{\text {dual }}=\Delta Q_{1}+\Delta Q_{2} \\
\Delta V_{o_{\text {dat }}}=\frac{\Delta Q_{\text {dual }}}{C}
\end{gathered}
$$

The capacitance current and voltage in Figure 3can be equivalent to the formula (8), as shown in Figure 4.

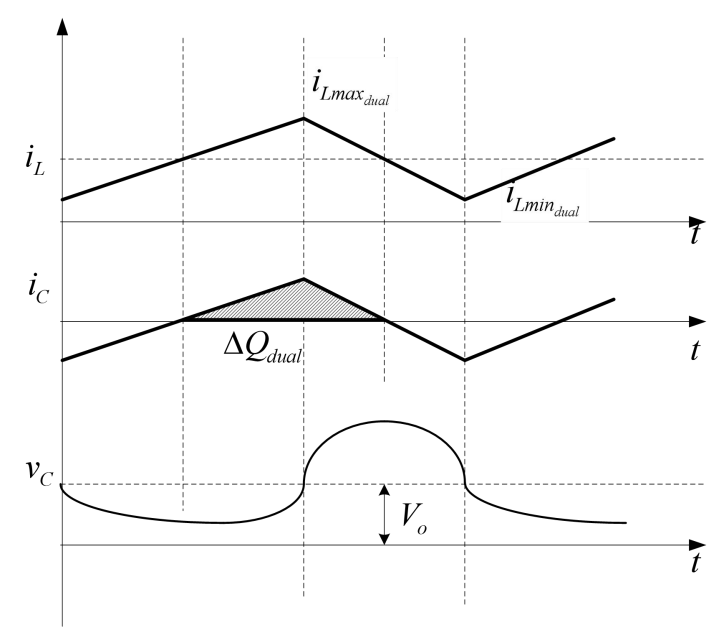

Fig.4 Equivalent diagram of capacitor voltage in double pulse modulation mode By the equivalent of figure 4 , we can come to the following:

$$
\Delta Q_{\text {dual }}=\frac{1}{2} \frac{\Delta I_{L-\text { dual }}}{2} \frac{T_{s}}{2}
$$

by comparing (7) and (16), can be obtained:

$$
\Delta Q_{\text {dual }}<\Delta Q_{\text {single }}
$$

Because of this, we can get the expression of the voltage ripple under the mode of single pulse width modulation and dual pulse width modulation. 


$$
\Delta V_{o-\text { dual }}<\Delta V_{o-\text { single }}
$$

Combined mode (13) and (18) can be seen that the output current and voltage ripple of the circuit are significantly suppressed when the circuit works in a dual pulse width modulation mode.

\section{Simulation Result}

In order to verify the principle of the previous analysis, this paper uses MATLAB to use the dual pulse width modulation mode Buck circuit simulation analysis, the specific simulation results shown in Table 1.

Table1 Double pulse modulation mode current, voltage ripple

\begin{tabular}{|c|c|c|c|c|c|}
\hline & Ripple1 & Ripple 2 & Ripple 3 & Ripple 4 & $\begin{array}{c}\text { Single } \\
\text { Pulse }\end{array}$ \\
\hline $\begin{array}{c}\text { Simulation Current } \\
\text { Ripple(mA) }\end{array}$ & 121 & 149 & 125 & 123 & 316 \\
\hline $\begin{array}{c}\text { Simulation Voltage } \\
\text { Ripple(mV) }\end{array}$ & 143 & 173 & 156 & 152 & 497 \\
\hline $\begin{array}{c}\text { Experiment Current } \\
\text { Ripple(mA) }\end{array}$ & 156 & 186 & 153 & 159 & 353 \\
\hline $\begin{array}{c}\text { Experiment Voltage } \\
\text { Ripple(mV) }\end{array}$ & 185 & 251 & 182 & 181 & 522 \\
\hline
\end{tabular}

\section{Conclusion}

In this paper, Buck circuit is used as a model to propose a dual pulse width modulation method which can suppress the output voltage ripple. The theoretical basis is given by the principle analysis. Finally, the accuracy of the theoretical analysis is verified by simulation.

\section{References}

[1]Dj.M. Maric, P.F. Meier and S.K. Estreicher: Mater. Sci. Forum Vol. 83-87 (1992), p. 119

[2]M.A. Green: High Efficiency Silicon Solar Cells (Trans Tech Publications, Switzerland 1987).

[3]Y. Mishing, in: Diffusion Processes in Advanced Technological Materials, edtied by D. Gupta Noyes Publications/William Andrew Publising, Norwich, NY (2004), in press.

[4]G. Henkelman, G.Johannesson and H. Jónsson, in: Theoretical Methods in Condencsed Phase Chemistry, edited by S.D. Schwartz, volume 5 of Progress in Theoretical Chemistry and Physics, chapter, 10, Kluwer Academic Publishers (2000).

[5]R.J. Ong, J.T. Dawley and P.G. Clem: submitted to Journal of Materials Research (2003)

[6]P.G. Clem, M. Rodriguez, J.A. Voigt and C.S. Ashley, U.S. Patent 6,231,666. (2001) 